\title{
Eine interessante Aberratio von Melitaea Athalia Esp.
}

Von Anatol R. v. Neumann-Spallart,

Zögling der k. k. Theresianischen Akademie in Wien.

Palpen dunkler als bei der normalen Form, Fühler oben schwärzlich, ohne Spur der hellen Ringelung, unten normal gefärbt.

\section{O berseite.}

Vorderflügel sehr verdunkelt, fast einfärbig schwarzbraun, mit nur schwachen Spuren der bräunlichen Binden; Fransen gescheckt.

H interflügel eintönig schwärzlichbraun, mit hellem, länglichem Fleck in der Mittelzelle und der Fleckenbinde vor dem Saume wie bei ab. navarina Sel.; am linken Hinterflügel stehen auch in Zelle $1-3$ je ein heller Fleck. Erwähnenswerth ist noch, dass die linke Oberseite einen bleichen Schimmer von der Mitte gegen den Saum hin zeigt, ein Anklang an Albinismus oder vielmehr Bleichsucht (Chlorochroismus, siehe Frauenfeld, Verh. d. Zool. Pot. Vereins. Wien 1853, III, pag. 40), wie derselbe öfters bei Epinephele Janira vorkommt; auf der rechten Seite ist nur gegen den Innenwinkel der Hinterflügel ein bleicher Schimmer bemerkbar.

Unterseite.

Vorderflügel an der Wurzel und in der Mittelzelle mit grossem rundlichen, schwarzen Fleck in bräunlichem Grunde, jede Zelle des Discus mit einer mässigen Strieme, die am Innenrande am dunkelsten, bis zum normal gefärbten Saumfelde, in dem die Kappenlinie fast verschwindet; Fransen wie oben.

Hinterflügel: Die Wurzelbinde und der Fleck der Mittelzelle schwärzlich begrenzt, saumwärts in dunklem Grunde die rostfarbige Fleckenbinde, welche an die schmutziggelbe Kappenlinie stösst. Fransen gelblich, schwach dunkel gescheckt. Bauch und Beine wenig dunkler als bei der Stammform.

Die Unterseite der Hinterflügel ähnelt am meisten Esper's Fig. 2 auf Tafel XXX, Bd. I.

Ein of fing ich gegen Ende Juli am sogenannten Sandberge bei Vöslau (Niederösterreich). 


\section{$2 \mathrm{BHL}$ Biodiversity Heritage Library}

Neumann von Spallart, Anatol. 1889. "Eine interessante Aberratio von Melitaea Athalia ESP." Wiener entomologische Zeitung 8, 92. https://doi.org/10.5962/bhl.part.20029.

View This Item Online: https://www.biodiversitylibrary.org/item/42656

DOI: https://doi.org/10.5962/bhl.part.20029

Permalink: https://www.biodiversitylibrary.org/partpdf/20029

\section{Holding Institution}

Smithsonian Libraries

\section{Sponsored by}

Smithsonian

\section{Copyright \& Reuse}

Copyright Status: NOT_IN_COPYRIGHT

This document was created from content at the Biodiversity Heritage Library, the world's largest open access digital library for biodiversity literature and archives. Visit BHL at https://www.biodiversitylibrary.org. 